\title{
Fructose-Fed Induced Metabolic Syndrome Model in Cynomolgus Monkeys
}

\author{
Shanshan Ding*, Changqing Zhang, Li Zhang, Yupeng Fang, Xin Zhang, Tao Jing and Shoutao Liu \\ WuXi AppTec, Wuzhong District, Suzhou, Jiangsu Province, China
}

\begin{abstract}
The incidences of obese and metabolic syndrome have risen dramatically in recent decades. The pathological conditions of metabolic syndrome greatly increase the risk factors of cardiovascular disease, type 2 diabetes and NASH. The over consumption of high-fructose in beverage has been considered may play a role in the causes. To better understand the association of excessive fructose intake and pathophysiological progressing for obesity, type 2 diabetes and $\mathrm{NASH}$, we assessed anthropometrics and metabolic parameters in a total of 71 cynomolgus monkeys after the consumption of high fructose diet within a 12 months period, including but not limited to body weight, body fat, $\mathrm{HbA1C}$, liver enzymes. All the assessment values showed as Mean $\pm \mathrm{SD}$, and have compared from baseline of pre-feeding of high fructose diet to the 12 months of post feeding. The result showed that about $13 \%$ monkeys were overt T2DM, 32\% monkeys became obese with an impaired IVGTT profile and 31\% monkeys obesity animals at last, many features of the metabolic syndrome such glucose and insulin impairment were existed in related cohorts. We demonstrated that dietary of high fructose induced metabolic syndrome in cynomolgus monkeys that provides a good translational animal model system to investigate obesity and metabolic syndrome pathogenesis, prevention and treatment.
\end{abstract}

Keywords: Cynomolgus monkey; Fructose; Metabolic syndrome model; Obese; Insulin resistance

\section{Introduction}

Obesity, a complex health issues, is epidemic continually rising in recent decades with an estimated figure of 14 billion worldwide [1]. It has been a predominantly healthy problem in westernized societies [24], for example in the US, $31 \%$ of the population is obese at 2003 [5]. In addition, many Asian, South American and African nations have also reported that obesity rates are increasing rapidly during the last decade [2,6-9]. Obesity develops because of a mismatch between energy intake and expenditure that results from behavior (feeding behavior and time spent active) and physiology (resting metabolism and expenditure when active). Both of these traits are affected by environmental and genetic factors [10].

The term "metabolic syndrome" dates back to at least the late 1950 s, but came into common usage in the late 1970s [11,12]. It can be initialed by obesity and developed with chronic disorders of insulin resistance, hypertension, impaired glucose tolerance, hyperinsulinemia and dyslipidemia characterized by elevated triglyceride and low HDL concentrations [13]. In 2000, approximately $32 \%$ of U.S. adults had the metabolic syndrome. In more recent years that figure has climbed to $34 \%$ [14-16].

Obesity and metabolic syndrome, both chronic illnesses lead to a consequent of several health problems, such as diabetes, dislipidemia and cardiovascular diseases, and the metabolic syndrome has been associated with a plethora of cancers including breast, pancreatic, colon and liver cancer [17-19].

Take no account of genetic factors, the dramatic increase in the numbers of obese and metabolic syndrome in Western societies reflects mostly changing environmental factors and is linked to reduced activity and perhaps also increased food intake.

Excessive caloric intake has been related to high-fat foods and diets high both in simple sugars such as sucrose and in high-fructose corn syrup (HFCS) as a source of fructose [20-22]. HFCS is now manufactured and used in many countries throughout the world [23], HFCS now represent $40 \%$ of all added caloric sweeteners [24], and it is the major source of caloric sweeteners in soft drinks and many other sweetened beverages and is also included in baked goods, canned fruits, jams and jellies, and dairy products in the United States [25]. Furthermore, the rise in the consumption of high-fructose corn syrup in beverages has paralleled the rise in the prevalence of obesity and the metabolic syndrome [26-28]. Meta-analyses have also suggested that the consumption of sugar sweetened beverages is related to the risk of diabetes, the metabolic syndrome, and cardiovascular disease [29].

Besides of the epidemiologic investigations, many studies of the etiology, patho-physiological progress and treatment to obesity and metabolic syndrome have been undertaken. Recently several articles report that the consumption of fructose sweetened beverages increases visceral adipose deposition and triglycerides levels [30,31], produces dyslipidemia, and decreases glucose tolerance/insulin sensitivity [32]. HFCS made by enzymatic isomerization of glucose to fructose was introduced as HFCS-42 (42\% fructose) and HFCS-55 (55\% fructose) in 1967 and 1977, respectively. It is one of the major fructose resources, and about two-thirds of all HFCS consumed in the United States are in beverages [26]. Unlike pathway of glucose metabolism, fructose is only metabolized by liver. The effects of high fructose diet to the liver has been also investigated, and reported that hepatic injury has induced by dietary fructose in a study with calorically controlled primates [33].

Animal models were useful tool to explore the inherent and/or extrinsic inducement of the disease, to understand disease development, progression and related complication, to evaluate the target drug efficacy and so on. Most of metabolic syndrome models use rodent because of their small size, short generation interval, easy availability and economic considerations, they can be obtained either spontaneously or induced

${ }^{*}$ Corresponding author: Shanshan Ding, WuXi AppTec, Wuzhong District, Suzhou, Jiangsu Province, China, Tel: +8651268837321; E-mail: ding_shanshan@wuxiapptec.com

Received September 14, 2017; Accepted October 16, 2017; Published October 17,2017

Citation: Ding S, Zhang C, Zhang L, Fang Y, Zhang X,et al. (2017) Fructose-Fed Induced Metabolic Syndrome Model in Cynomolgus Monkeys. J Vet Sci Technol 8: 478. doi: $10.4172 / 2157-7579.1000478$

Copyright: @ 2017 Ding S, et al. This is an open-access article distributed under the terms of the Creative Commons Attribution License, which permits unrestricted use, distribution, and reproduction in any medium, provided the original author and source are credited. 
by chemicals or dietary or surgical manipulations or transgenic/knockout and/or by combination thereof. However, nonrodent models are urgently needed as a valuable supplement to rodents which have better patho-physiological metabolism similarities to humans. Nonhuman primates have been increasingly used in biomedical research as they are more anatomically and physiologically homologous to humans as compared to other animal models (e.g., rats, pigs) and share many other characteristics with humans. They are opportunistic omnivores which is same as human. Currently, studies related to obesity/diabetes research are moving toward using non-human primates (NHPs) [34-36].

Cynomolgus monkeys belong to old world monkeys, are sexually dimorphic with respect to size. Adult males are considerably larger than females, weighing 5-9 $\mathrm{kg}(11-20 \mathrm{lb})$ compared to the 3-6 $\mathrm{kg}(6.6-$ $13.2 \mathrm{lb}$ ) of females [37]. The typical life span of the cynomolgus monkey ranges from 25-30 years [38], they are susceptible to age-related pathologies commonly observed in humans, such as obesity, and diabetes (and complications therefrom, including diabetic neuropathy and retinopathy) [39]. Along with the genome has been sequenced, making it's possible to compare gene code with human. In a word, the cynomolgus monkey has the third-largest range of any primate species, behind only humans and rhesus macaques, is an ideal species using in metabolic syndrome animal model.

In this article, the anthropometrics, and clinical pathological parameters, as well as the glycemic and lipidemia profiles data have been collected and presented from a total of 71 cynomolgus monkeys in a longitudinal study of experiment tried to mimic the etiology of human metabolic syndrome, to explore the link of high fructose diet with metabolic syndrome in large animal. Assessments have analyzed from a baseline of pre-feeding, and 3, 6, 9 to 12 months of post-feeding high-fructose diet, and compared to baseline from each post-feeding assessment.

\section{Materials and Methods}

\section{Animal and husbandry information}

The 61 males and 10 females of adults cynomolgus monkeys were obtained from JinGang Inc., Hainan providence, China and used in this study. They aged from 11-15 years and were kept in door cages, in paired housing at the vivarium facility of and accessibility of cage have accredited by AAALAC. Environment enrichment including mirror and different functional toys are provided for each animal. The room(s) were controlled and monitored for relative humidity (targeted mean range $40 \%$ to $70 \%$ ) and temperature (targeted mean range 18 to $26^{\circ} \mathrm{C}$ ) with 10 to 20 air changes/hour. The rooms were on a 12 hours light/dark cycle except when interruptions are necessitated by study activities. Animal using protocols for all the animal studies were approved by the Institutional Animal Care and Use Committee (IACUC) (WuXi AppTec, com., Suzhou, Jiangsu province, The People's Republic of China).

\section{Diet information}

A commercial monkey chow diet (Lab Diets $5 \mathrm{C} 48$ is equivalent to LabDiets certified Primate Diet 5048, modified for import into China, Advance Protocol Old World Primate; PMI, St. Louis, MO, USA) was provided ad libitum to all the monkeys. This diet is a complete life cycle diet that provides $30 \%$ energy as protein, $12 \%$ energy as fat (ether extract), and $57 \%$ energy as carbohydrate. In addition, a $500 \mathrm{ml}$ of fruitflavored (Archer Daniels Midland Company) 15\% fructose sweetened beverage (75 $\mathrm{g}$ of fructose) were also provided ad libitum. Reverses osmosis water was available to all animals, ad libitum. Enriched with seasonal fruits and vegetables were provided daily in accordance with the Association for Assessment and Accreditation of Laboratory Animal Care (AAALAC) regulations and guidelines [40].

\section{Anthropometrics assessment}

Body weight, body fat percentage, waistline and Body Mass Index (BMI): Body weight, body fat percentage, waistline which circled navel and body mass index (BMI, body weight/crown-rump length 2 , $\mathrm{kg} / \mathrm{m}^{2}$ ) were assessed at the time of pre diet-induction as baseline, then every three months after diet induction. Total body fat composition was determined by using dual-energy x-ray absorptiometry (DEXA, HOLOGIC Discovery), a sensitive technique for measuring body fat, which has been previously validated for the determination of body composition in monkeys [41]. The percentage level (\%) total mass of fat divided by total body mass (see below formula).

$\%$ Fat $=100 \times$ fat mass $/($ fat mass+lean mass $)$

Clinical pathology panel: Blood samples were collected as the same pattern described above for anthropometrics assessments. The whole blood sample ( $\mathrm{K}_{2}$-EDTA anticoagulation) was collected for analysis of hematology and plasma collection. The hematological assessments were analyzed by using an automatic analyzer (ADVIA 2120, Siemens).

The plasma sample have obtained by centrifugation of whole blood sample with $\mathrm{K}_{2}$-EDTA anticoagulation, and stored with an aliquot of whole blood sample at $-70^{\circ} \mathrm{C}$ freezer until future analyze of glycemic indices.

Serum sample was also collected at same time and used for measuring clinical chemistry panel by using an automatic analyzer (HITACHI 7180, Hitachi High-Tech Science Systems Corporation). Clinical chemistry is including but not limit total cholesterol, triglyceride, non-esterified fatty acid (NEFA), liver and renal function parameter.

Glycemic indices of fasted glucose, fasted Insulin and Hemoglobin A1c: Plasma glucose concentrations were measured by Biosen C-Line glucose and lactate analyzer (EKF Diagnostics, Germany) which using enzymatic-amperiometric method. Plasma insulin concentrations were measured using ELISA kits (Mercodia AB, Uppsala, Sweden). Hemoglobin A1c percentage was detected by DCA Vantage Analyzer (Siemens Healthineers) through monoclonal antibody agglutination reaction, the calculation formula is:

\section{$\%$ HbAlc $=($ HbAlc/Total Hemoglobin $) \times 100$}

Intravenous Glucose Tolerance Tests (IVGTTs): IVGTTs were performed quarterly. The animals were fasted for overnight 16 $\mathrm{hrs}$ and anesthetized with Zoletil 50 (Virbac S.A.) at about $3 \mathrm{mg} / \mathrm{kg}$ intramuscularly (i.m.) and then supplemental Zoletil 50 with half dosage of initial dose level was given intramuscularly (i.m.) if needed. The cephalic and/or saphenous veins were cannulated separately for glucose infusion and blood collection. Two baseline blood samples were collected into BD tube contain $\mathrm{K}_{2}$-EDTA at -5 , and 0 minutes. Subsequently, $300 \mathrm{mg} / \mathrm{kg}$ of $50 \%$ dextrose was intravenously infused within a 30 second period. Additional blood samples were collected at $3,5,10,20,30$, and 60 minutes after glucose infusion. Blood samples were gently inverted several times and immediately placed on wet ice prior to centrifugation at $2-8^{\circ} \mathrm{C}$ and $3000 \mathrm{~g}$ for 10 minutes to obtain plasma. Plasmas were stored at $-70^{\circ} \mathrm{C}$ or lower until analysis.

Stratification of study cohorts: The animals have been stratified into the study cohorts of lean, obese, insulin resistance and T2DM 
based on their initial assessments of anthropometrics, clinical path parameters and glycemic indices prior to high-fructose induction. The stratification of each cohort was described as Table 1.

The classified values of hemoglobin A1c percentage and body weight for stratification were referring to glycemic indices in cynomolgus described in chapter 14, nonhuman primates in biomedical research with the modification, volume 2 by Jan Wagner [42], and adapted from Cawthon Lang [37].

Statistical analysis: Values are presented as the mean \pm SD. A two-tailed $p$ value $<0.05$ was considered to be statistically significant. The AUC for glucose and insulin, the clearance of glucose during the IVGTTs was calculated by using the linear-log trapezoidal rule [43] Phoenix WinNonlin software (version 6.2.1, Pharsight, Mountain View, CA).

\section{Results}

As Table 1 shown, there were 54 lean monkeys, 12 obese monkeys, 5 pre-diabetes and none of diabetic monkeys at pre-feeding of high fructose diet baseline time, after 12 months of high fructose consumption, 17 monkeys have remained in lean cohort, the monkey numbers in obese cohort has increased to 22 from 12.23 pre-diabetes animals and 9 T2DM animals were overt. In other word, about $13 \%$ of the study cohort animals were developed T2DM, and 23 animals in pre-diabetes status which is probably in the process of going into T2DM cohort. In a nutshell, almost all animals developed components of the metabolic syndrome. The detail information is listed in Table 2.

\section{Body weight, body fat, waistline and Body Mass Index (BMI)}

All the monkeys initially gained weight significantly, from $8.07 \pm$ $1.05 \mathrm{~kg}$ to $9.16 \pm 2.23 \mathrm{~kg}$, on the high-fructose diet in the first 3 months, and then the mean body weight slightly increased and get peak in 6 months $(9.27 \pm 2.29 \mathrm{~kg})$, subsequently, the body weight were almost unchanged in the following months, but on the whole, the body weight increased by $13 \%$ at 12 months $(\mathrm{p}<0.001)$. Animal body weight profile in 12-month is shown in Figure 1a.

The initial body fat percentage (\%) was $28.5 \pm 8.21 \%$, and then increased to $36.7 \pm 8.82 \%, 38.3 \pm 9.52 \%$ at 3 months and 6 months respectively, but in 12 months, the body fat percentage was slightly decreased to $37.6 \pm 9.11 \%$ (Figure $1 \mathrm{~b}$ ). The waistline and BMI were $40.23 \pm 6.89 \mathrm{~cm}$ and $38.62 \pm 7.24 \mathrm{~kg} / \mathrm{m}^{2}$ at the beginning, those two parameters were also increased significantly in the first few months, which were reached the peak $48.20 \pm 8.82 \mathrm{~cm}$ and $44.43 \pm 8.64 \mathrm{~kg} /$ $\mathrm{m}^{2}$ in 6 months respectively. Whereafter, both two parameters were decreased a bit at the end of the measurement (Figure 1c and 1d). Overall, the profile of body weight, body fat percentage, waistline and BMI have similar curve, the increased percentage at 12 months of body fat percentage, waistline and BMI were $32 \%(\mathrm{p}<0.001), 14 \%(\mathrm{p}<0.001)$, $13 \%(\mathrm{p}<0.001)$.

In the last measurement at 12 months, the body weights were highly correlated with their BMIs $\left(\mathrm{r}^{2}=0.89\right.$, Figure $\left.2 \mathrm{c}\right)$, and waistline $\left(r^{2}=0.54\right.$, Figure $\left.2 b\right)$. The body fat percentage and body weights were also correlated well $\left(r^{2}=0.21\right.$, Figure $\left.2 \mathrm{a}\right)$, but not well with the former two values. And the correlation between body weights and $\mathrm{HbAlc}$ was the least one among the four analytical items $\left(\mathrm{r}^{2}=0.01\right.$, Figure $\left.2 \mathrm{~d}\right)$.

\section{Fasting lipid and lipoprotein concentration}

Fasting total cholesterol (TCHO) concentration presented zigzag changed during 1 year (Table 3), and the concentration was changed from $2.72 \pm 0.68 \mathrm{mmol} / \mathrm{L}$ at baseline to $3.11 \pm 2.03 \mathrm{mmol} / \mathrm{L}$ at $12 \mathrm{months}$ $(+14 \%, \mathrm{P}>0.05)$. Triglycerides (TG) concentration had increasing tendency overall, the concentration at 12 months was almost triple of baseline $(+195 \%, \mathrm{p}<0.05$, Table 3$)$. In addition, the concentration of NEFA was about 2-fold increased at 12 months versus baseline level $(\mathrm{P}<0.001$, Table 3$)$.

\section{Liver and kidney panel, hematology data}

The mean concentrations of alanine aminotransferase, aspartate aminotransferase and g-glutamyltransferase gradually increased by $23 \%(\mathrm{P}<0.01), 30 \%(\mathrm{P}<0.001)$, and $11 \%(\mathrm{P}<0.01)$ at 12 months respectively. In the meanwhile, the alkaline phosphatase concentration decreased by $11 \%(\mathrm{P}<0.05)$ at 12 months (Table 4$)$.

As for kidney functional parameters, the mean urea concentration increased $(+24 \%, \mathrm{P}<0.001)$ at 12 months. Nevertheless, the creatinine concentration mainly decreased $(-6 \%, \mathrm{P}<0.001$, Table 4$)$. The hematology parameters did not show any obvious changing during the study (data not show).

\section{Fasting glucose and insulin concentration, IVGTT profile}

After 12 months high-fructose diet induction in cynomolgus monkeys, the mean fasting glucose concentrations basically did not change, and the mean fasting insulin concentrations were also not changed significantly. However, the area under the curve (AUC $\left.{ }_{60 \mathrm{mins}}\right)$ for both glucose and insulin concentrations during intravenous glucose tolerance testing were increased by $18 \%$ (7596 $\pm 1356 \mathrm{~min}^{*} \mathrm{mg} /$ $\mathrm{dL}$ at baseline, $8906 \pm 2035 \mathrm{~min} \cdot \mathrm{mg} / \mathrm{dL}$ at 12 months) and 25\% (3290 \pm $2622 \mathrm{~min} \cdot \mu \mathrm{U} / \mathrm{mL}$ at baseline, $4114 \pm 2383 \mathrm{~min} \cdot \mu \mathrm{U} / \mathrm{mL}$ at $12 \mathrm{months}$ ). Correspondingly, the glucose clearance was decreased from $2.82 \pm 0.91$ $\mathrm{mL} / \mathrm{min} / \mathrm{kg}$ at baseline to $2.01 \pm 0.89 \mathrm{~mL} / \mathrm{min} / \mathrm{kg}$ at 12 months (Table 5). Mean $\mathrm{HbAlc}$ and fructosamine increased gradually during the study. The correlation of $\mathrm{HbAlc}$ with fasting glucose $\left(\mathrm{r}^{2}=0.70\right)$, fasting insulin $\left(r^{2}=0.02\right)$, fructosamine $\left(r^{2}=0.82\right)$ and total cholesterol $\left(r^{2}=0.50\right)$ were evaluated at 12 months (Figure 3 ).

\begin{tabular}{|c|c|c|}
\hline Cohort & Hemoglobin A1c (\%) & Total body fat (\%) \\
\hline Lean & $\leq 4.5$ & Male: $<35 \%$, Female: $<40 \%$ \\
\hline Obesity & $\leq 4.5$ & Male: $\geq 35 \%$, Female: $\geq 40 \%$ \\
\hline Pre-diabetes & $4.5>-\leq 5.5$ & -- \\
\hline Diabetes & $>5.5$ & -- \\
\hline
\end{tabular}

Table 1: Stratifying the monkeys based on Hemoglobin A1c (\%) and total body fat $(\%)$.

\begin{tabular}{|c|c|c|c|}
\hline Cohort & Baseline & $\mathbf{6}$ months & $\mathbf{1 2}$ months \\
\hline Lean & 54 & 22 & 17 \\
\hline Obesity & 12 & 30 & 22 \\
\hline Pre-diabetes & 5 & 16 & 23 \\
\hline T2DM & 0 & 3 & 9 \\
\hline
\end{tabular}

Table 2: Animal number changing during 12-months high-fructose diet induction.

\begin{tabular}{|c|c|c|c|}
\hline Time & $\begin{array}{c}\text { Total Cholesterol } \\
(\mathbf{m m o l} / \mathbf{L})\end{array}$ & Triglycerides $\mathbf{( m m o l} / \mathbf{L})$ & NEFA (mmol/L) \\
\hline Baseline & $2.72 \pm 0.68$ & $0.40 \pm 0.20$ & $0.41 \pm 0.35$ \\
\hline 3 Months & $3.11 \pm 0.99$ & $1.05 \pm 0.81$ & $0.63 \pm 0.34$ \\
\hline 6 Months & $2.85 \pm 0.90$ & $0.68 \pm 0.50$ & $0.94 \pm 0.32$ \\
\hline 9 Months & $2.83 \pm 1.19$ & $1.03 \pm 1.12$ & $0.74 \pm 0.35$ \\
\hline 12 Months & $3.11 \pm 2.03$ & $1.18 \pm 2.85$ & $0.90 \pm 0.29$ \\
\hline
\end{tabular}

Table 3: Fasting lipid and lipoprotein concentration (mean $\pm S D, n=71$ ) during 1 year high-fructose induction. 

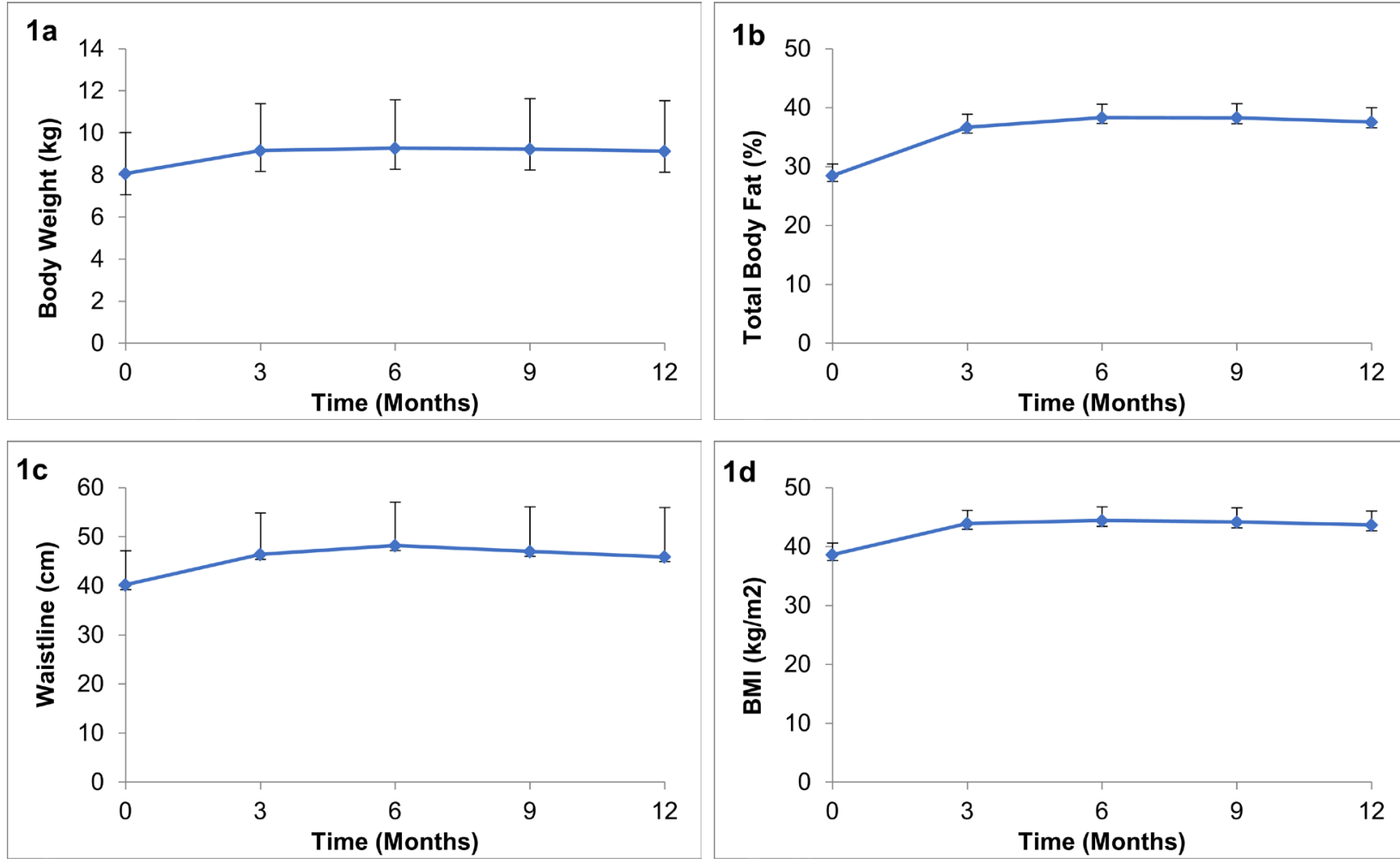

Figure 1: The effect of a high-fructose diet on body weight (1a), body fat (1b), waistline (1c) and BMI (1d) during the study. Error bars show SEM.
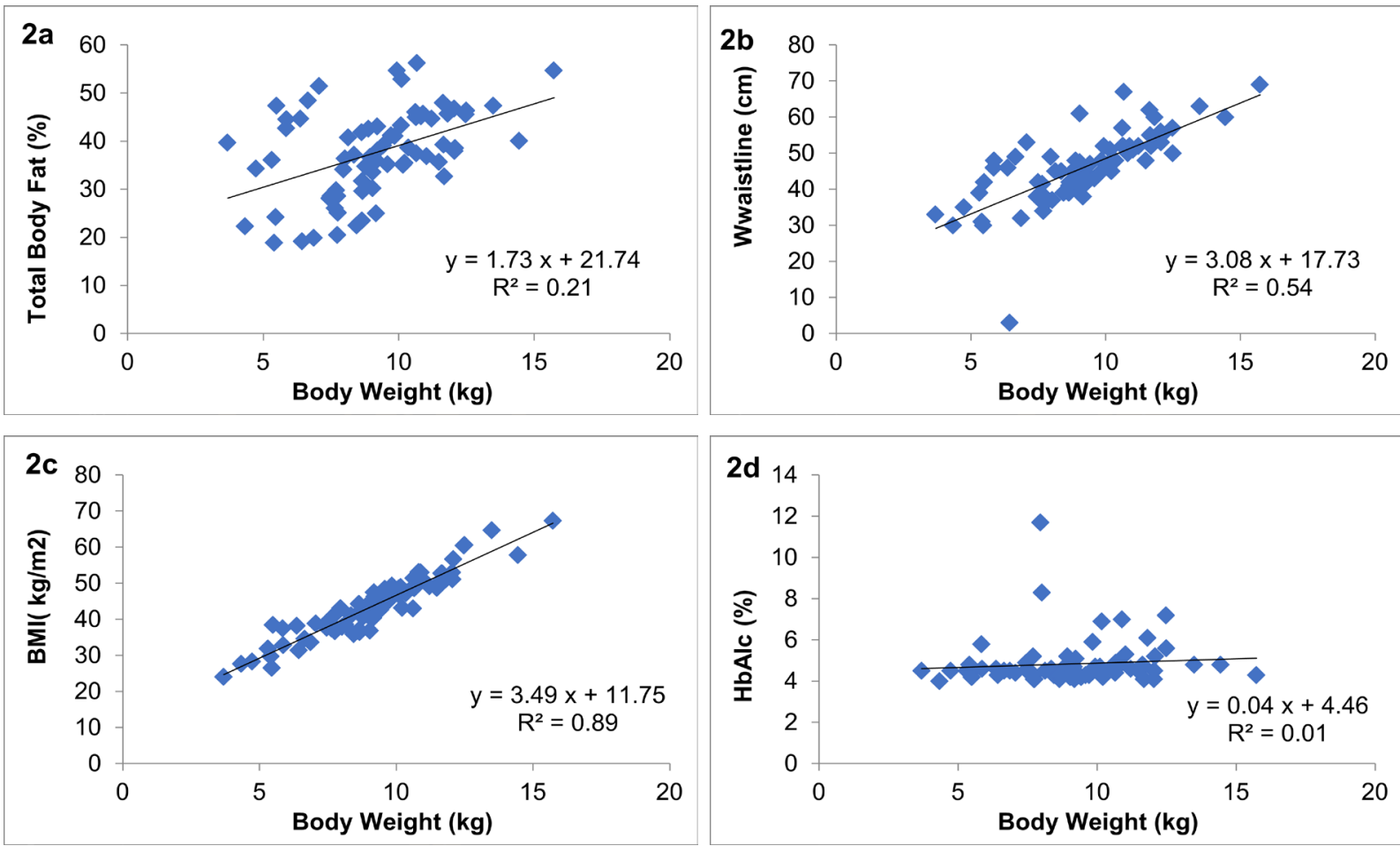

Figure 2: The correlations between body weight and body fat (2a), body weight and waistline (2b), body weight and BMI (2c), body weight and $\mathrm{HbA} 1 \mathrm{c}(2 \mathrm{~d})$ at 12 months $(n=71)$. 

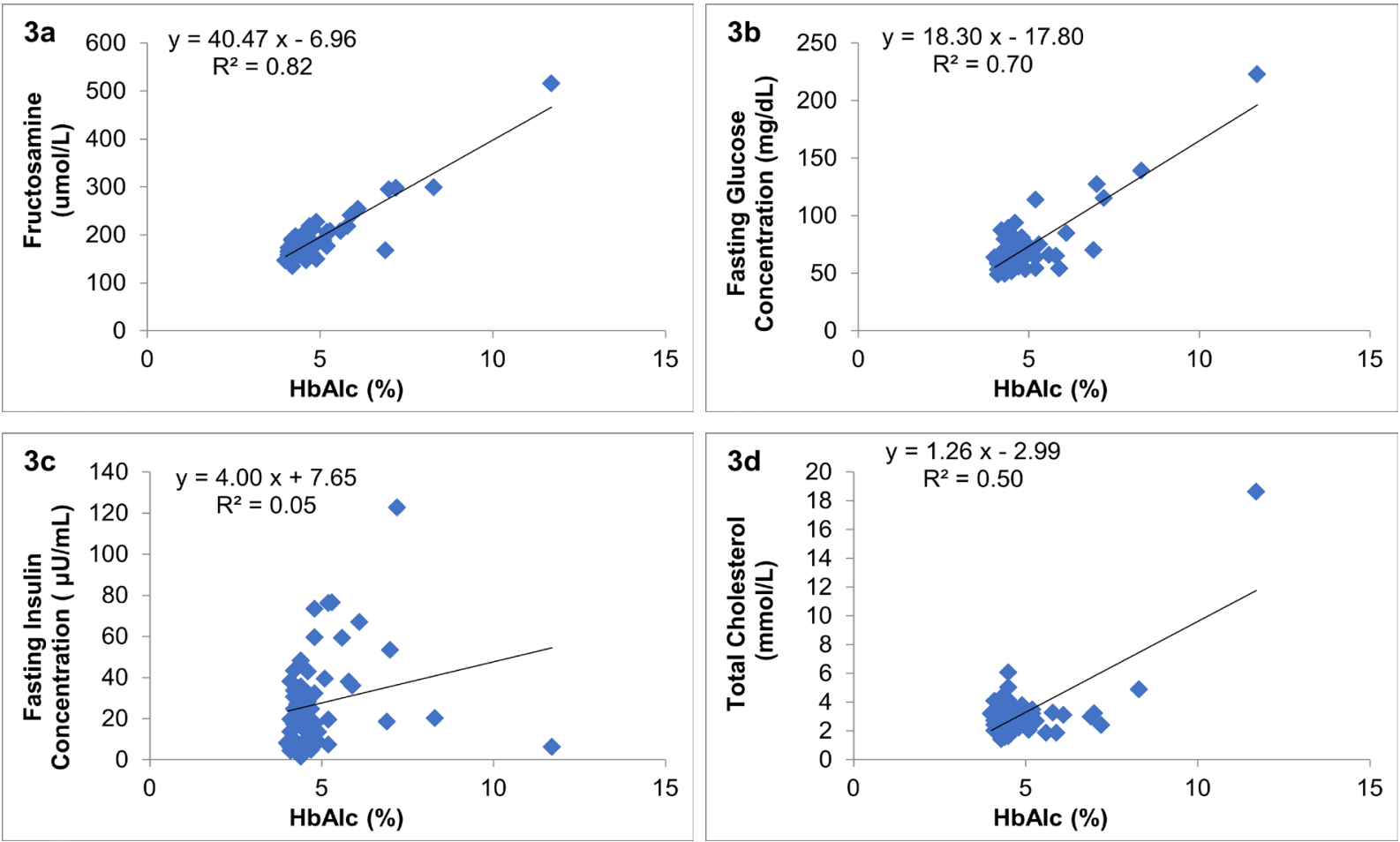

Figure 3: The correlations between HbAlc and fructosamine (3a), HbAlc and fasting glucose concentration (3b), HbAlc and fasting insulin concentration (3c), HbAlc and Total Cholesterol (3d) at 12 months $(n=71)$.

In order to make longitudinal comparison of metabolic relative parameter in different cohorts during the study period, the 71 animals at baseline and 6 months were also divided into 4 cohorts, by working backward from the data on 12 months based upon our hierarchical criteria. The mean fasting glucose concentrations were increased significantly $(105.1 \pm 53.6 \mathrm{mg} / \mathrm{dL}$ at 12 months versus $75.3 \pm 11.4 \mathrm{mg} /$ $\mathrm{dL}$ at baseline). The Glucose $\mathrm{AUC}_{0-60 \mathrm{~min}}$ in all cohorts increased more or less, and the amount of increase in T2DM cohort was highest. In addition, the glucose clearance gradually decreased in all cohorts, and the decreasing ratio was also highest in diabetes cohort. Except lean cohort, the mean $\mathrm{HbAlc}$ had different increased ratios, without doubt increased most significantly in T2DM cohort. There is no obvious changing in mean fasting insulin concentrations in this comparison at different cohorts, but insulin $\mathrm{AUC}_{0-60 \text { min }}$ increased in all cohort except T2DM cohort (Table 6).

The glucose and insulin concentration profiles in different cohort shown in Figures 4 and 5 during 1 year induction. And the insulin concentration profiles presents in Figure 5. We can find that the glucose and insulin concentration curves did not change in lean cohort (Figures $4 \mathrm{a}$ and $5 \mathrm{a}$ ), and the glucose concentrations increased in other three study cohorts, particularly in T2DM cohort (Figure 4b-4d). In obesity and pre-diabetes cohorts, the insulin concentrations both increased, especially in pre-diabetes cohort at 12 months, the insulin concentration has a significantly elevation, which match the insulin resistant characteristic (Figure $5 \mathrm{~b}$ and $5 \mathrm{c}$ ). As for diabetes cohort (Figure 5d), the insulin concentration decreased, indicated that the pancreas islet would not secrete enough insulin to help regulating the glucose metabolism, so the glucose concentrations did not return to normal at 60 minutes during IVGTT procedure.
The horizontal comparison of glucose and insulin concentration profiles in IVGTT at 12 months presents in Figure 6, beyond doubt, the level of glucose concentrations were highest in T2DM cohort, however, the insulin concentrations were only higher than lean cohort. Both glucose and insulin concentrations were lowest in lean cohort among four study cohorts. In pre-diabetes cohort, the glucose concentration is slightly higher than obesity cohort, for insulin concentrations, mean concentrations at several time points were higher than obesity cohort, on the contrary to most other time points. Fructosamine concentrations in pre-diabetes were higher than lean and obesity cohorts, but lower than T2DM cohort (Table 6).

\section{Discussion}

In this investigation, only 10 females of 71 animals were used, both sexes can develop age-related metabolic syndrome diseases. Females have their highest birth rates around 10 years of age and completely stop bearing young by age 24 [44], all used female animals were age 11-15 years which were in that range. But 10 animals were not enough to make statistics analysis in this long-term study, based on the consideration, the data of 71 animals was analyzed as a whole.

Beverages sweetened with HFCS may have a link with the epidemic of obesity [45-47], HFCS provide more energy intake that lead to weight gain, and also obesity rate rising. According to the laws of thermodynamics, which state that energy can neither be created nor destroyed, the imbalance between intake and expenditure requires that we also have the capacity to temporarily store energy, and fat is preferred to be energy storage, since it is much denser than carbohydrate and also does not require large amounts of water for storage, therefore either food intake being too high, expenditure being too low (through low resting metabolic rate and/or activity expenditures), or a combination 

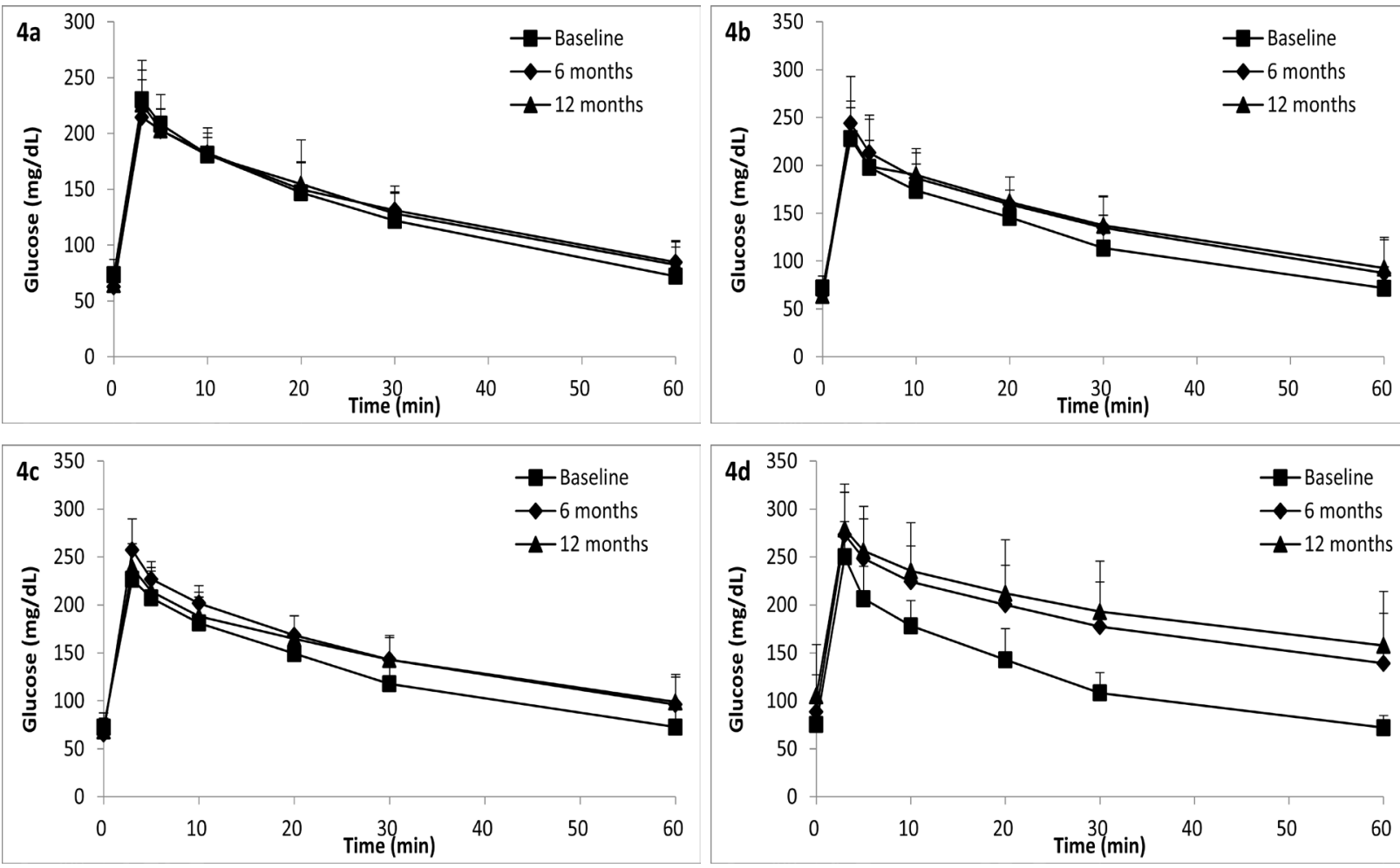

Figure 4: The glucose concentrations in normal $(4 a, n=17)$, obesity $(4 b, n=22)$, pre-diabetes $(4 c, n=23)$ and T2DM (4d, $n=9)$ group during this study.

\begin{tabular}{|c|c|c|c|c|c|c|}
\hline Time & $\begin{array}{c}\text { Alanine } \\
\text { Aminotransferase (U/L) }\end{array}$ & $\begin{array}{c}\text { Aspartate } \\
\text { Aminotransferase (U/L) }\end{array}$ & $\begin{array}{c}\text { Alkaline } \\
\text { Phosphatase (U/L) }\end{array}$ & g-glutamyl transferase (U/L) & Urea $(\mathrm{mmol} / \mathrm{L})$ & Creatinine $(\mu \mathrm{mol} / \mathrm{L})$ \\
\hline Baseline & $41.8 \pm 22.6$ & $33.3 \pm 8.85$ & $100 \pm 36.7$ & $47.4 \pm 19.0$ & $5.81 \pm 1.03$ & $88.9 \pm 19.4$ \\
\hline 3 Months & $44.4 \pm 25.4$ & $39.8 \pm 10.6$ & $100 \pm 42.2$ & $50.0 \pm 20.2$ & $6.76 \pm 1.70$ & $86.0 \pm 21.4$ \\
\hline 6 Months & $47.7 \pm 29.3$ & $42.8 \pm 12.8$ & $92.8 \pm 39.9$ & $49.1 \pm 20.6$ & $7.04 \pm 1.42$ & $84.5 \pm 21.3$ \\
\hline 9 Months & $51.1 \pm 35.3$ & $39.9 \pm 13.0$ & $101 \pm 41.3$ & $51.9 \pm 23.7$ & $6.62 \pm 1.64$ & $82.0 \pm 20.1$ \\
\hline 12 Months & $51.6 \pm 33.2$ & $43.3 \pm 11.8$ & $88.5 \pm 46.3$ & $52.6 \pm 24.2$ & $7.22 \pm 1.33$ & $83.2 \pm 19.2$ \\
\hline
\end{tabular}

Table 4: Liver and kidney panel parameters (mean $\pm \mathrm{SD}, \mathrm{n}=71$ ) during 1 year high-fructose induction.

of both [10]. In our experiment, animals were housed in-door that lead to less activity and provided fructose-sweetened beverages, all those mimic human behavior that changing in eating habits and activity patterns. The number of obese and metabolic syndrome monkeys was changed gradually, the obese, pre-diabetes and T2DM monkeys were up to 30,16 , and 3 respectively at 6 months, and at the end of the study, there was only remaining 17 lean monkeys, it's no weird that the obesity animals decreased to 22 , because pre-diabetes and diabetes monkeys increased to 23 and 9 (Table 2), the disease is in progressing. We can also found that mean body weight, body fat percentage, waistline and BMI changed significantly in the first 3 months, and then almost reach a plateau, however all four parameters increased significantly at 12 months versus baseline. In one study, rhesus monkey body weights were detected monthly, the changing profile is similar with our study [48].

For decades, BMI is as an indirect measure to define obese, WHO accepted that people with a BMI index $>25$ but $<30$ are said to be overweight, and people with an index $>30$ are defined as obese, but there are several well-recognized problems with this index. Firstly, it does not reflect body fatness changes very well when a person is also changing his or her height over time, it's not suitable for adolescent. Secondly, body builders and some athletes, who have developed large amounts of muscle tissue, may also be misclassified as obese, but the obese people carry around excessive amounts of body fat [10]. If we apply BMI to animal, there is another challenge that the monkey is not standing animal, using four limbs to climb, that make it difficult to define the height of the animal. As technological development, body fat percentage level, which is the direct indicator for obese, can be measured by DEXA, it is seemed to be better index of obesity in this primate species when compared with other obesity markers such as body weight and morphometry [49]. In one study, it suggested that normal female animals with \%Fat of 25-35, boundary female animals had \%Fat had of $35-40$, and obese female animals' \%Fat was over 40 [50]. According to the criterion of American Council on Exercise [51], the percentage body fat of woman is higher than man in all groups, and woman with $40 \%$ plus and man with $30 \%$ plus body fat percentage are considerate as obese. So we assumed that body fat percentage which was over $40 \%$ in female monkeys and 35\% in male monkeys would be classified as obese in this study.

Hemoglobin A1c a form of hemoglobin that is measured primarily 


\begin{tabular}{|c|c|c|c|c|c|c|c|}
\hline Time & HbA1c \% & $\begin{array}{l}\text { Fructosamine } \\
\qquad(\mu \mathrm{mol} / \mathrm{L})\end{array}$ & $\begin{array}{c}\text { Fasting Glucose } \\
\text { Concentration (mg/ } \\
\mathrm{dL})\end{array}$ & $\begin{array}{l}{\text { Glucose } A U C_{0-60 \mathrm{~min}}}_{\left(\mathrm{min}^{*} \mathrm{mg} / \mathrm{dL}\right)}\end{array}$ & $\begin{array}{c}\text { Glucose Clearance } \\
(\mathrm{mL} / \mathrm{min} / \mathrm{kg})\end{array}$ & $\begin{array}{c}\text { Fasting Insulin } \\
\text { Concentration }(\mu \mathrm{U} / \\
\mathrm{mL})\end{array}$ & $\begin{array}{l}\text { Insulin } A U C_{0-60 \min } \\
\quad\left(\mathrm{min}^{\star} \mu U / \mathrm{mL}\right)\end{array}$ \\
\hline Baseline & $4.22 \pm 0.22$ & NA & $72.9 \pm 13.2$ & $7596 \pm 1356$ & $2.82 \pm 0.91$ & $24.6 \pm 34.4$ & $3290 \pm 2622$ \\
\hline 6 months & $4.59 \pm 0.82$ & $180 \pm 31.2$ & $67.7 \pm 17.9$ & $8857 \pm 1799$ & $2.16 \pm 0.82$ & $20.0 \pm 15.2$ & $3486 \pm 2438$ \\
\hline 12 months & $4.84 \pm 1.14$ & $189 \pm 50.8$ & $70.8 \pm 24.8$ & $8906 \pm 2035$ & $2.01 \pm 0.89$ & $27.0 \pm 21.2$ & $4114 \pm 2383$ \\
\hline
\end{tabular}

Table 5: The mean metabolic parameters during IVGTT at baseline and 12 months $(n=71)$, NA mean not available due to do not detect.

\begin{tabular}{|c|c|c|c|c|c|c|c|c|}
\hline Group & Time & HbA1c\% & $\begin{array}{l}\text { Fructosamine } \\
\qquad(\mu \mathrm{mol} / \mathrm{L})\end{array}$ & $\begin{array}{c}\text { Fasting Glucose } \\
\text { Concentration } \\
\text { (mg/dL) }\end{array}$ & $\begin{array}{l}{\text { Glucose } A U C_{0-60}}^{\text {min }}\left(\mathrm{min}^{*} \mathrm{mg} / \mathrm{dL}\right)\end{array}$ & $\begin{array}{c}\text { Glucose } \\
\text { Clearance }(\mathrm{mL} / \\
\text { min/kg) }\end{array}$ & $\begin{array}{c}\text { Fasting Insulin } \\
\text { Concentration }(\mu \mathrm{U} / \\
\mathrm{mL})\end{array}$ & $\begin{array}{l}\text { Insulin } A U C_{0-60 \mathrm{~min}} \\
\quad\left(\mathrm{~min}^{*} \mu \mathrm{U} / \mathrm{mL}\right)\end{array}$ \\
\hline \multirow{3}{*}{ Lean $(N=17)$} & Baseline & $4.18 \pm 0.15$ & NA & $73.4 \pm 13.7$ & $7674 \pm 1353$ & $2.79 \pm 0.80$ & $14.3 \pm 8.98$ & $2331 \pm 1193$ \\
\hline & 6 months & $4.32 \pm 0.19$ & $172 \pm 13.2$ & $62.7 \pm 6.79$ & $8129 \pm 795$ & $2.28 \pm 0.43$ & $12.2 \pm 8.62$ & $2527 \pm 1533$ \\
\hline & 12 months & $4.29 \pm 0.14$ & $174 \pm 11.2$ & $64.7 \pm 10.1$ & $8008 \pm 1118$ & $2.35 \pm 0.74$ & $15.2 \pm 9.65$ & $2699 \pm 1298$ \\
\hline \multirow{3}{*}{$\begin{array}{l}\text { Obesity } \\
(\mathrm{N}=22)\end{array}$} & Baseline & $4.24 \pm 0.21$ & NA & $72.0 \pm 12.4$ & $7500 \pm 1675$ & $2.92 \pm 1.12$ & $17.7 \pm 14.4$ & $3663 \pm 1682$ \\
\hline & 6 months & $4.30 \pm 0.19$ & $168 \pm 16.1$ & $65.5 \pm 12.0$ & $8416 \pm 1872$ & $2.44 \pm 0.99$ & $19.3 \pm 11.1$ & $4124 \pm 2832$ \\
\hline & 12 months & $4.33 \pm 0.16$ & $169 \pm 16.0$ & $63.8 \pm 9.66$ & $8518 \pm 1541$ & $2.18 \pm 1.06$ & $25.7 \pm 12.2$ & $4677 \pm 2545$ \\
\hline \multirow{3}{*}{$\begin{array}{l}\text { Pre-diabetes } \\
\qquad(\mathrm{N}=23)\end{array}$} & Baseline & $4.19 \pm 0.24$ & NA & $72.6 \pm 14.8$ & $7614 \pm 1183$ & $2.81 \pm 0.69$ & $27.8 \pm 42.9$ & $2569 \pm 1778$ \\
\hline & 6 months & $4.55 \pm 0.26$ & $181 \pm 20.3$ & $65.6 \pm 10.0$ & $8963 \pm 1241$ & $2.19 \pm 0.71$ & $20.1 \pm 12.9$ & $3270 \pm 2151$ \\
\hline & 12 months & $4.83 \pm 0.22$ & $184 \pm 21.0$ & $68.5 \pm 13.6$ & $8795 \pm 1453$ & $1.96 \pm 0.68$ & $29.3 \pm 22.4$ & $4470 \pm 2557$ \\
\hline \multirow{3}{*}{ T2DM $(\mathrm{N}=9)$} & Baseline & $4.36 \pm 0.29$ & NA & $75.3 \pm 11.4$ & $7635 \pm 1092$ & $2.65 \pm 1.12$ & $52.6 \pm 57.7$ & $6030 \pm 5376$ \\
\hline & 6 months & $5.91 \pm 1.78$ & $225 \pm 59.6$ & $88.7 \pm 38.6$ & $11036 \pm 2570$ & $1.47 \pm 0.57$ & $36.2 \pm 26.0$ & $4289 \pm 3101$ \\
\hline & 12 months & $7.17 \pm 1.90$ & $277 \pm 100$ & $105 \pm 53.6$ & $11836 \pm 3140$ & $1.06 \pm 0.58$ & $46.9 \pm 32.8$ & $4500 \pm 1309$ \\
\hline
\end{tabular}

Table 6: The mean metabolic parameters by groups at baseline and 12 months. NA means not available due to do not detect.

to identify the three-month average plasma glucose concentration. The recommendations of the American Diabetes Association (ADA), International Diabetes Federation, and World Health Organization [52-54], diagnosis of diabetes mellitus should be based on either an oral glucose tolerance test (OGTT) or hemoglobin A1c (HbA1c) findings, and $\mathrm{HbAlc} \geq 6.5 \%(48 \mathrm{mmol} / \mathrm{mol})$ will be diagnosed to diabetes. The $\mathrm{HbA} 1 \mathrm{c}$ has several advantages compared with the fasting plasma glucose and OGTT, including greater convenience (fasting not required), greater preanalytical stability, and less day-to-day perturbations during stress and illness [53]. There is a positive correlation between glucose and $\mathrm{HbAlc}$, when blood glucose levels are high, more glucose binds to hemoglobin in the red blood cells and the higher the glycated hemoglobin. Experimental evidence clearly shows that normal fasting serum glucose concentrations for monkeys are about $30 \mathrm{mg} / \mathrm{dL}$ lower than for normal humans [34,55], by that analogy, HbA1c is also lower in non-human primate, we conceived that $\mathrm{HbA} 1 \mathrm{c} \geq 5.5$ is T2DM, less than or equal to 5.5 and great than 4.5 is pre-diabetes. But with caution to use $\mathrm{HbAlc}$ as cut point. On the one hand, it is important to take age and race/ethnicity into consideration, for example it's not suitable for using in children and adolescents [56,57]. On the other hand, several diseases or condition can influence the $\mathrm{HbAlc}$ value, lower $\mathrm{HbAlc}$ values are found in conditions such as recent transfusion and increased erythropoiesis secondary to hemolysis or blood loss, chronic kidney disease (CKD), anemia [58-60], to the contrary, asplenia and Iron deficiency anemia will lead a higher HbAlc values [61,62]. We also take above concerns into account, the hematology results were in normal range in adult monkeys [63].

Several articles report that triglycerides level were increased as the consequences of ingesting sugar-sweetened beverage [30-32,61], in our study, triglycerides level increased significantly after 1 year of beverage intake. Studies indicate that fructose consumption and have been associated with fatty liver [64,65] and hepatic fibrosis [66] in people, higher exposures to dietary fructose result in the development of hepatic lipidosis in nonhuman primates when consumed ad libitum for periods equivalent to $\geq 1$ human year and ALT, AST, GGT increased after 6 weeks of high fructose diet exposure [67], the detected biomarkers (NEFA, TCHO, ALT, AST, GGT in Tables 3 and 4) changing trend in our study also reveal this possibility.

In a manner analogous to the determination of glycated hemoglobin, fructosamine testing determines the fraction of total serum proteins that have undergone glycation (the glycated serum proteins). Except glycated lipoprotein and glycated globulin, the main component of fructosamine is glycated albumin, albumin is the most abundant protein in blood, fructosamine levels typically reflect albumin glycation, albumin has a half-life of approximately 20 days, the plasma fructosamine concentration reflects relatively recent (2-3 week) changes in blood glucose [68]. More and more studies are being conducted fructosamine as a glycemic control indicators [69-71], the data showed that fructosamine concentrations (Table 6) in T2DM cohorts were higher than any other cohorts, and in pre-diabetes cohort, the level was far less than T2DM cohort but slightly higher than lean and obese cohorts. Fructosamine is possible to evaluate shortterm glycemic control, but we need to know that the diseases such hyperthyroidism and hypothyroidism $[71,72]$ and nephritic syndrome [73] can lead to inaccurate result, because of the impact of protein (albumin) metabolism.

The association of obesity with type 2 diabetes is the ability of obesity to engender insulin resistance, insulin resistance plays an essential role in the development of the metabolic syndrome and T2DM $[19,74]$. The mechanisms of obesity-associated insulin resistance may include endocrine (fatty acids, adipokines and other adipocyte factors), inflammatory, neuronal pathways, and cell-intrinsic mechanisms (oxidative stress, ectopic fat storage, mitochondrial dysfunction and ER stress) [75]. Factors thought to contribute to insulin resistance include diet, exercise, smoking, stress, gene and age [76]. Insulin resistance usually connotes resistance to the effects of insulin on glucose uptake, metabolism, or storage. Insulin resistance in obesity and type 2 diabetes is manifested by decreased insulin-stimulated glucose transport and metabolism in adipocytes and skeletal muscle and by impaired suppression of hepatic glucose output [77-79]. Intravenous glucose tolerance test (IVGTT) is one of the best established methods 

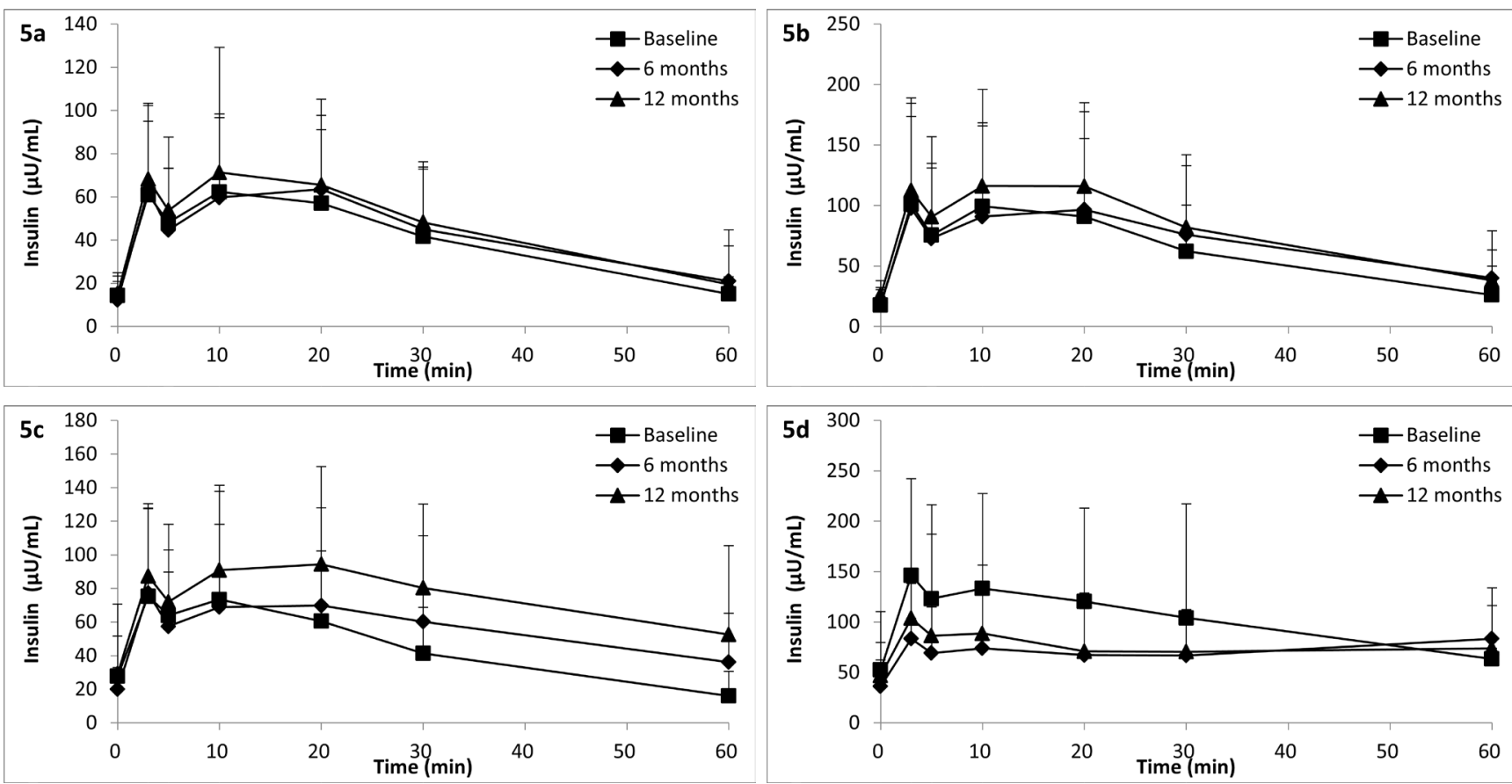

Figure 5: The insulin concentrations in normal $(5 a, n=17)$, obesity $(5 b, n=22)$, pre-diabetes $(5 c, n=23)$ and T2DM $(5 d, n=9)$ group during this study.
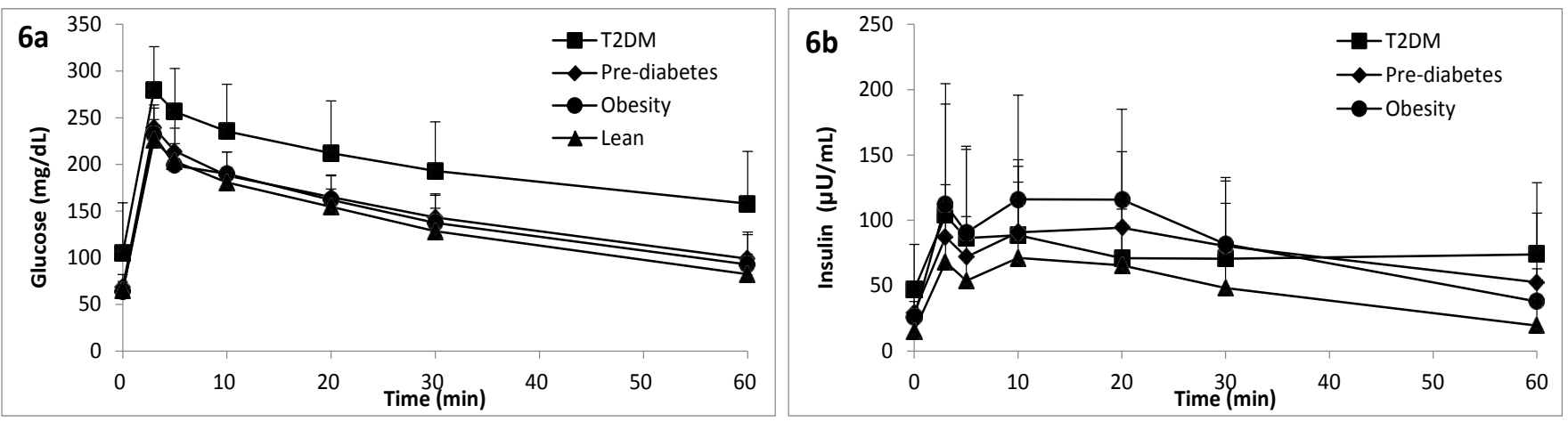

Figure 6: The glucose (6a) and insulin (6b) responses during IVGTT at 12 months in cymomolgus monkeys with diet induced metabolic models.

of measuring insulin resistance [80], this test is widely used in monkeys [81] for the decades. In this article, we performed IVGTT to evaluate the glucose tolerance and insulin sensitivity and beta cell function. The data show that glucose tolerance and insulin tolerance were impaired in the pre-diabetes and T2DM cohorts (Table 6; Figures 4-6) at 6 months and 12 months respectively, the impairment degree was exacerbated as time went by. The inability of the $\beta$-cells to produce sufficient insulin in a condition of hyperglycemia is what characterizes the transition from insulin resistance to T2DM [19], the study present that hyperglycemia and hypoinsulimia are as characters in T2DM cohort, while in prediabetes cohort, hyperglycemia and hyperinsulimia are observed in the monkeys.

\section{Conclusion}

More and more evidence show that there is a link increasing high-fructose consumption result in obese and metabolic syndrome in human. We demonstrated that, consumption of a high-fructose diet in cynomolgus monkeys during 1 year period produces a series of diseases that have similar diseases symptoms of human, who show a metabolic progression from obese, insulin resistance and impaired glucose tolerance to T2DM, making the NHP mode is valuable for studying obesity and metabolic syndrome pathogenesis, prevention and treatment. The rapid metabolic changes occur also provide the possibility to evaluate these processes in long-term compliance with dietary and pharmaceutical interventions studies that cannot practically be performed in human.

\section{Acknowledgements}

Thanks Nianbo Lu, Lei Le, Tan Xu, and Bing Xiao for technical assistance. Thanks WuXi Lab Testing Division for their help and support, especially Shanhai Zong in bioanalysis department for large molecule analysis and Laboratory services for clinical pathology analysis. 


\section{References}

1. O'Neill S, O'Driscoll L (2015) Metabolic syndrome: a closer look at the growing epidemic and its associated pathologies. The Authors Obesity Reviews published by John Wiley \& Sons Ltd., on behalf of International Association for the Study of Obesity (IASO).

2. Likitmaskul S, Kiattisathavee $P$ (2003) Increasing prevalence of type 2 diabetes mellitus in Thai children and adolescents associated with increasing prevalence of obesity. J Pediatr Endocrinol Metab 16: 71-77.

3. Caterson ID, Gill TP (2002) Obesity: epidemiology and possible prevention Best Pract Res Clin Endocrinol Metab 16: 595-610.

4. Engeland A, Bjorge T, Selmer RM, Tverdal A (2003) Height and body mass index in relation to total mortality. Epidemiology 14: 293-296.

5. Centers for Disease Control and Prevention. US Department of Health and Human Services. Accessed on January 2004.

6. Arroyo P, Loria A, Fernandez V, Flegal KM, Kuri-Morales P, et al. (2000) Prevalence of pre-obesity and obesity in urban adult Mexicans in comparison with other large surveys. Obes Res 8: 179-185.

7. Dorosty AR, Reilly JJ, Siassi F (2002) Obesity in Iranian children. Arch Dis Child: 87: 388-391.

8. Sanja S, Kain J, Uauy R (2007) The association between changes in heigh and obesity in Chilean preschool children: 1996-2004. Obesity 15: 1012-1022.

9. Hernandez B, Gortmake SL, Colditz GA, Peterson KE, Laird NM, et al. (1999) Association of obesity with physical activity, television programs and other forms of video viewing among children in MexicoCity. Int J Obes Relat Metab Disord 23: 845-854.

10. Speakman JR (2004) Obesity: The Integrated Roles of Environment and Genetics. J Nutr 134: 2090S-2105S.

11. Joslin EP (1921) The prevention of diabetes mellitus. JAMA 76: 79-84.

12. Kylin $E$ (1923) Studies of the hypertension-hyperglycemia-hyperuricemia syndrome (German). Zentralbl Inn Med 44: 105-127.

13. Reaven GM (1988) Banting lecture 1988. Role of insulin resistance in human disease. Diabetes 37: 1595-1607.

14. Ford ES (2010) Prevalence and correlates of metabolic syndrome based on a harmonious definition among adults in the U.S. J Diabetes 2: 180-193.

15. Ford ES, Giles WH, Mokdad AH (2004) Increasing prevalence of the metabolic syndrome among U.S. adults. Diabetes Care 27: 2444-2449.

16. Mozumdar A, Liguori G (2011) Persistent increase in prevalence of metabolic syndrome among U.S. adults: NHANES III to NHANES 1999-2006. Diabetes Care 34: 216-219.

17. Guh DP, Zhang W, Bansback N, Amarsi Z, Birmingham CL, et al. (2009) The incidence of co-morbidities related to obesity and overweight: a systematic review and meta-analysis. BMC Public Health 9: 88.

18. Brown WV, Fujioka K, Wilson PW, Woodworth KA (2009) Obesity: why be concerned? Am J Med 122: S4-11.

19. McGarry, JD (2002) Banting lecture 2001: dysregulation of fatty acid metabolism in the etiology of type 2 diabetes. Diabetes. 51: 7-18.

20. Bray GA, Popkin BM (1998) Dietary fat intake does affect obesity! Am J Clin Nutr 68: 1157-1173.

21. Young LR, Nestle M (2002) The contribution of expanding portion sizes to the US obesity epidemic. Am J Public Health 92: 246-249.

22. Elliott SS, Keim NL, Stern JS, Teff K, Havel PJ (2002) Fructose, weight gain, and the insulin resistance syndrome. Am J Clin Nutr 76: 911-922.

23. Vuilleumier $S$ (1993) Worldwide production of high-fructose syrup and crystalline fructose. Am J Clin Nutr 58(suppl): 733S-736S

24. Putnam JJ, Allshouse JE (1999) Food consumption, prices and expenditures, 1970-97. US Department of Agriculture Economic Research Service statistical bulletin no. 965, April 1999. Washington, DC: US Government Printing Office 1999.

25. Hanover LM, White JS (1993) Manufacturing, composition, and applications of fructose. Am J Clin Nutr 58(suppl): 724S-732S.

26. Bray GA, Nielsen SJ, Popkin BM (2004) Consumption of high-fructose corn syrup in beverages may play a role in the epidemic of obesity. Am J Clin Nutr 79: $537-543$

27. Bray GA (2007) How bad is fructose? Am J Clin Nutr 86: 895-896.

28. Dekker MJ, Su Q, Baker C, Rutledge AC, Adeli K (2010) Fructose: a highly lipogenic nutrient implicated in insulin resistance, hepatic steatosis, and the metabolic syndrome. Am J Physiol Endocrinol Metab 299: E685-E694.

29. Malik VS, Popkin BM, Hu FB (2010) Sugar-sweetened beverages and risk of metabolic syndromeand type 2 diabetes: a meta-analysis. Diabetes Care 33 2477-2483.

30. Stanhope KL, Bremer AA, Medici V (2011) Consumption of fructose and high fructose corn syrup increase postprandial triglycerides, LDL-cholesterol and apolipoprotein-B in young men and women. J Clin Endocrinol Metab 96: E1596-E1605.

31. Maersk M, Belza A, Stødkilde-Jørgensen H, Ringgaard S, Chabanova E, et al (2012) Sucrose-sweetened beverages increase fat storage in the liver, muscle and visceral fat depot: a 6-mo randomized intervention study. Am J Clin Nutr 95: 283-289.

32. Stanhope KL, Schwarz JM, Keim NL, Griffen SC, Havel PJ, et al. (2009) Consuming fructose-sweetened, not glucose-sweetened, beverages increases visceral adiposity and lipids and decreases insulin sensitivity in overweight/ obese humans. J Clin Invest 119: 1322-1334.

33. Kavanagh K, Wylie AT, Tucker KL, Hamp TJ, Gharaibeh RZ, et al. (2013) Dietary fructose induces endotoxemia and hepatic injury in calorically controlled primates. Am J Clin Nutr 98: 349-357.

34. Wagner JD, Cline JM, Shadoan MK, Bullock BC, Rankin SE, et al. (2001) Naturally occurring and experimental diabetes in cynomolgus monkeys: a comparison of carbohydrate and lipid metabolism and islet pathology. Toxicol Pathol 29: 142-148.

35. Kemnitz JW, Elson DF, Roecker EB, Baum ST, Bergman RN, et al. (1994) Pioglitazone increases insulinsensitivity, reduces blood glucose, insulin and lipid levelsand lowers blood pressure in obese, insulin resistant rhesusmonkeys. Diabetes 43: 204-211.

36. Kim SY, Lutty GA, Johnson MA, McLeod DS, Alexander T, et al. (2005) Neutrophils are associated with capillaryclosure in spontaneously diabetic monkey retinas. Diabetes 54: 1534-1542.

37. Cawthon Lang KA. Primate Factsheets: Long-tailed macaque (Macaca fascicularis) Taxonomy, Morphology, \& Ecology. Primate Info Net.

38. Eric Van Esch J, de Rijk EPCT, Cline JM, Buse E, Weinbauer GF, et al. (2008) Summary comparison of female reproductive system in human and the cynomolgus monkey (Macaca fascicularis). Toxicol Pathol 36: 171S-172S

39. Wolfe-Coote S (2005) The laboratory primate. Academic Press, pp: 449-466

40. AAALAC International and NIH guidelines as reported in the "Guide for the Care and Use of Laboratory Animals", National Research Council-ILAR, Revised 2011

41. Narita H, Ohkubo F, Yoshida T, Cho F, Yoshikawa $Y$ (1994) Measuring bone mineral content and soft tissue mass in living the cynomolgus monkey. Jikken Dobutsu 43: 261-265.

42. Wagner JD, Cann JA, Li ZH (2012) James Harwood Jr. Chapter 14 - Diabetes and Obesity Research using Nonhuman Primates. Nonhuman Primates Biomed Res 2: 699-732.

43. Gabrielsson J, Weiner D (2000) Non-compartmental analysis. In Pharmacokinetic and Pharmacodynamic Data Analysis. Swedish Pharmaceutical Press, Stockholm. Concepts \& Applications, 3rd edn. Gabrielsson J, Weiner D (eds.), pp: 141-146.

44. van Noordwijk MA, van Schaik CP (1999) The Effects of Dominance Rank and Group Size on Female Lifetime Reproductive Success in Wild Long-tailed Macaques, Macaca fascicularis. Primates 40: 105-130.

45. Ferder L, Ferder MD, Inserra F (2010) The role of high-fructose corn syrup in metabolic syndrome and hypertension. Curr Hypertens Rep 12: 105-112.

46. Ludwig DS, Peterson KE, Gortmaker SL (2001) Relation between consumption of sugar-sweetened drinks and childhood obesity: a prospective, observational analysis. Lancet 357: 505-508.

47. Raben A, Vasilaras TH, Moller AC, Astrup A (2002) Sucrose compared with artifical sweeteners: different effects on ad libitum food intake and body weight 
Citation: Ding S, Zhang C, Zhang L, Fang Y, Zhang X, et al. (2017) Fructose-Fed Induced Metabolic Syndrome Model in Cynomolgus Monkeys. J Vet Sci Technol 8: 479. doi: 10.4172/2157-7579.1000479

Page 10 of 10

after $10 \mathrm{wk}$ of supplementation in overweight subjects. Am J Clin Nutr 76: 721 729

48. Bremer AA, Stanhope KL, Graham JL, Cummings BP, Wang W, et al. (2011) Fructose-Fed Rhesus Monkeys: A Nonhuman Primate Model of Insulin Resistance, Metabolic Syndrome, and Type 2 Diabetes. Clin Trans Sci 4: 243252

49. Yang C, Hiromi O, Narita H, Ohtoh K, Yoshida T, et al. (2003) Ratio of Leptin to Adiponectin as an Obesity Index of Cynomolgus Monkeys (Macaca fascicularis). Exp Anim 52: 137-143.

50. ACE (2009) What are the guidelines for percentage of body fat loss? American Council on Exercise (ACE). Ask the Expert Blog. December 2, 2009

51. Organization WHO (2011) Use of Glycated Haemoglobin (HbA1c) in the Diagnosis of Diabetes Mellitus 2011

52. American Diabetes Association (2016) Classification and diagnosis of diabetes. Sec. 2. In Standards of Medical Care in Diabetes-2016. Diabetes Care 39 (Suppl. 1): S13-S22.

53. International Expert C (2009) International Expert Committee report on the role of the $\mathrm{A} 1 \mathrm{C}$ assay in the diagnosis of diabetes. Diabetes Care 32: 1327-1334.

54. Wagner JD, Kavanagh K, Ward GM, Auerbach BJ, Harwood HJ, et al. (2006) Old World Nonhuman Primate Models of Type 2 Diabetes Mellitus. ILAR J 47: 259-271.

55. Cowie CC, Rust KF, Byrd-Holt DD, Gregg EW, Ford ES, et al. (2010) Prevalence of diabetes and high risk for diabetes using A1C criteria in the U.S. population in 1988-2006. Diabetes Care 33: 562-568.

56. Nowicka P, Santoro N, Liu H, Lartaud D, Shaw MM, et al. (2011) Utility of hemoglobin A1c for diagnosing prediabetes and diabetes in obese children and adolescents. Diabetes Care 34: 1306-1311.

57. Little RR, Roberts WL (2009) A review of variant hemoglobins interfering with hemoglobin A1c measurement. J Diabetes Sci Technol 3: 446-451.

58. Ahmad J, Rafat D (2013) HbA1c and iron deficiency: A review. Diabetes Metab Syndr 7: 118-122.

59. Panzer S, Kronik G, Lechner K, Bettelheim P, Neumann E, et al. (1982) Glycosylated hemoglobins (GHb): an index of red cell survival. Blood 59: 13481350.

60. Sundaram RC, Selvaraj N, Vijayan G, Bobby Z, Hamide A, et al. (2007) Increased plasma malondialdehyde and fructosamine in iron deficiency anemia: effect of treatment. Biomed Pharmacother 61: 682-685.

61. Hashimoto K, Noguchi S, Morimoto Y, Hamada S, et al. (2008) A1C but not serum glycated albumin is elevated in late pregnancy owing to iron deficiency. Diabetes Care 31: 1945-1948.

62. Xie L, Xu F, Liu S, Ji Y, Zhou Q, et al. (2013) Age- and Sex-Based Hematological and Biochemical Parameters for Macaca fascicularis. PLoS ONE 8: e64892.

63. Assy N, Nasser G, Kamayse I, Nseir W, Beniashvili Z, et al. (2008) Soft drink consumption linked with fatty liver in the absence of traditional risk factors. Can J Gastroenterol 22: 811-816.

64. Welsh JA, Sharma A, Abramson JL, Vaccarino V, Gillespie C, et al. (2010)
Caloric sweetener consumption and dyslipidemia among US adults. JAMA 303 1490-1497.

65. Abdelmalek MF, Suzuki A, Guy C, Unalp-Arida A, Colvin R, et al. (2010) Increased fructose consumption is associated with fibrosis severity in patients with nonalcoholic fatty liver disease. Hepatology 51: 1961-1971.

66. Roohk HV, Zaidi AR (2008) A review of glycated albumin as an intermediate glycation index for controlling diabetes. J Diabetes Sci Technol 2: 1114-1121.

67. Ribeiro RT, Macedo MP, Raposo JF (2016) HbA1c, fructosamine, and glycated albumin in the detection of dysglycaemic conditions. Curr Diabetes Rev 12 14-19.

68. Suzuki S, Koga M (2014) Glycemic control indicators in patients with neonata diabetes mellitus. World J Diabetes 5: 198-208.

69. Ford HC, Lim WC, Crooke MJ (1987) Hemoglobin A1 and serum fructosamine levels in hyperthyroidism. Clin Chim Acta 166: 317-321.

70. Sako Y, Umeda F, Hashimoto T, Haji M, Nawata H (1989) Serum fructosamine in assessment of diabetic control and relation to thyroid function. Horm Metab Res 21: 669-672.

71. Constanti C, Simo JM, Joven J, Camps J (1992) Serum fructosamine concentration in patients with nephrotic syndrome and with cirrhosis of the liver: the influence of hypoalbuminaemia and hypergammaglobulinaemia. Ann Clin Biochem 29: 437-442.

72. DeFronzo RA, Ferrannini E (1991) Insulin resistance. A multifaceted syndrome responsible for NIDDM, obesity, hypertension, dyslipidemia and atherosclerotic cardiovascular disease. Diabetes Care 14: 173-194.

73. Qatanani M, Lazar MA (2007) Mechanisms of obesity-associated insulin resistance: many choices on the menu. Genes Dev 21: 1443-1455.

74. Kelly GS (2000) Insulin Resistance: Lifestyle and Nutritional Interventions Altern Med Rev 5: 109-132.

75. Hribal ML, Oriente F, Accili D (2002) Mouse models of insulin resistance. Am J Physiol Endocrinol Metab 282: E977-E981.

76. Saltiel AR, Kahn CR (2001) Insulin signalling and the regulation of glucose and lipid metabolism. Nature 414: 799-806.

77. Kahn BB, Flier JS (2000) Obesity and insulin resistance. J Clin Investigation 106: 473-481.

78. Muniyappa R, Lee S, Chen H, Quon MJ (2008) Current approaches for assessing insulin sensitivity and resistance in vivo: advantages, limitations, and appropriate usage. Am J Physiol Endocrinol Metab 294: E15-26.

79. Wu D, Yue F, Zou C, Chan P, Alex Zhang Y (2012) Analysis of glucose metabolism in cynomolgus monkeys during aging. Biogerontology 13: 147-155

80. Vaughan KL, Szarowicz MD, Herbert RL, Mattison JA (2014) Comparison of anesthesia protocols for intravenous glucose tolerance testing in rhesus monkeys. J Med Primatol 43: 162-168.

81. Jones CW, Reynolds WA, Hoganson GE (1980) Streptozotocin Diabetes in the Monkey: Plasma Levels of Glucose, Insulin, Glucagon, and Somatostatin with Corresponding Morphometric Analysis of Islet Endocrine Cells. Diabetes Jul 29: $536-546$ 